Article

\title{
Factors Influencing the Ability to Achieve Valued Outcomes among Older Long-Term Unemployed People
}

\author{
Nienke Velterop ${ }^{1,2}$, Jac van der Klink ${ }^{1,3,4}$, Sandra Brouwer ${ }^{1,2, *}$, Hilbrand Oldenhuis ${ }^{2}$ and Louis Polstra ${ }^{2}$ \\ ${ }^{1}$ Department of Health Sciences, Community and Occupational Medicine, University Medical Centre Groningen, \\ University of Groningen, 9713 AV Groningen, The Netherlands; E-Mails: nienkevelterop@gmail.com (N.V.), \\ sandra.brouwer@umcg.nl (S.B.) \\ ${ }^{2}$ Centre of Applied Labour Market Research, Hanze University of Applied Sciences, 9747 AS Groningen, The Netherlands; \\ E-Mails: h.k.e.oldenhuis@pl.hanze.nl (H.O.), I.polstra@pl.hanze.nl (L.P.) \\ 3 Tilburg School of Social and Behavioural Sciences, Tilburg University, 5037 AB Tilburg, The Netherlands; \\ E-Mail: j.j.l.vdrklink@tilburguniversity.edu \\ ${ }^{4}$ Optentia, North-West University, 1900 Vanderbijlpark, South Africa \\ * Corresponding author
}

Submitted: 28 March 2019 | Accepted: 18 February 2020 | Published: 20 March 2020

\begin{abstract}
This qualitative study aims to explore the valuable functionings-things that people consider to be important-of the older long-term unemployed and their ability to achieve valued outcomes. Semi-structured interviews were conducted with 20 long-term unemployed people aged 45 and over. Participants were included through purposeful sampling. The theoretical frameworks of the latent deprivation theory and the capability approach were used to develop an interpretive analysis. Nine valuable functionings were identified: social contact, feeling appreciated, structure, feeling useful, meaningfulness, autonomy, financial resources, paid work, and being active. These valuable functionings were partly accessible through the activities that people performed, varying from physically active and physically passive activities to informal work. The functionings of meaningfulness, autonomy, financial resources, and paid work seemed to be difficult to achieve. We identified three groups. The first consisted of people whose work status changed when they entered the benefit system; for them paid work was still a valuable functioning, and they experienced the most difficulties in achieving valued outcomes. The second group also experienced a change in work status once they started to receive benefits, but those people adapted to their new situation by attributing greater value to other functionings. The third group had no change in work status, e.g., housewives who had applied for a benefit because they were not able to make ends meet after a divorce. This group did not experience a loss of functionings due to unemployment, nor did they try to achieve other functionings. The results of this study indicate a need for a more personalized, tailor-made approach, with an emphasis on an individual's valued outcomes instead of on rules and obligations.
\end{abstract}

\section{Keywords}

benefits; capability approach; latent deprivation theory; long-term unemployment; inclusion; older people; valuable functionings; welfare

\section{Issue}

This article is part of the issue "Institutions of Inclusion and Exclusion" edited by J. Cok Vrooman (Utrecht University, The Netherlands/The Netherlands Institute for Social Research|SCP, The Netherlands) and Marcel Coenders (Utrecht University, The Netherlands/The Netherlands Institute for Social Research |SCP, The Netherlands).

(C) 2020 by the authors; licensee Cogitatio (Lisbon, Portugal). This article is licensed under a Creative Commons Attribution 4.0 International License (CC BY). 


\section{Introduction}

Work is not always gratifying and can even have negative consequences. Graeber $(2018$, p. 11) stated that many workers hold bullshit jobs, "a form of paid employment" he says "that is so completely pointless, unnecessary, or pernicious that even the employee cannot justify its existence even though, as part of the conditions of employment, the employee feels obliged to pretend that this is not the case." According to him, such jobs largely occur in the private sector, particularly in the fields of finance, law, human resources, public relations, and consultancy. In a population of 100,000 workers, Dur and van Lent (2019) found that $8 \%$ perceive their jobs as socially useless. Most of these workers had jobs in finance and law or in jobs with simple and routine manual tasks, such as machine operators, assemblers, or order pickers. Even though there is a growing group of workers who consider their job to be useless or empty (Graeber, 2018; Paulsen, 2014), they also strive for a valuable occupation. A meaningful job not only provides an income but also important latent benefits such as structured time, activity, collective purpose, social identity/status, and social contact (Jahoda, 1982). In many European countries, social security programs provide financial compensation as a safety net for the unemployed (Social Security Administration, 2014). But the unemployed have less access to the so-called latent benefits of work than those who are employed (Feather \& Bond, 1983; Paul \& Batinic, 2010; Selenko, Batinic, \& Paul, 2011; Stiglbauer \& Batinic, 2012). The deprivation of these latent benefits leads to lower levels of mental health (Jahoda, 1982). Fryer and Fagan (1993) reported research that showed that this isn't always the case. The mental health of the unemployed can improve due to adaptive coping (Fryer, 1998). The impacts of unemployment on the latent benefits also differ according to the family member with men, women, and children in the household being affected differently (Fryer \& Fagan, 2003).

In a review about the latent and manifest benefits (LAMB) scale, Muller and Waters (2012) stated that the relationship between access to the latent and manifest benefits of employment and psychological well-being is not direct or linear, but complex.

European countries developed social activation programs to support unemployed people in finding a job, even if it means accepting a bullshit job (van Berkel, de Graaf, \& Sirovatka, 2012). It is debated whether this is a good strategy because, on an individual level, the costs can be higher than the benefits (Thomson, 2019; Timmermann, 2018). Nevertheless, society profits if as many people as possible work, since long-term unemployment increases the risk of poverty, exclusion, and health deprivation (European Commission, 2015).

In Western Europe, older workers face a much higher risk than their younger colleagues of long-term unemployment once they have lost their jobs (Duell, Thurau, \& Vetter, 2016; European Commission, 2015). Only $17 \%$ of older people who had been unemployed for one to two years were re-employed. This percentage was even lower (approximately 10\%) for older workers who had been unemployed for two years or more. Activation programs with a focus on the supply side of reintegration efforts such as job search assistance or training in specific skills (Nybom, 2013), have not been very successful for the older unemployed (de Graaf-Zijl, van der Horst, Erken, \& Luginbuhl, 2015; Ranzijn, 2004). Age discrimination is one of the problems that these people face (Equinet, 2012; Porcellato, Carmichael, Hulme, Ingham, \& Prashar, 2010; van Dalen, Henkens, \& Schippers, 2009, 2010). A lack of up-to-date information about the labour market, no adequate network, and negative self-perceptions may also be barriers (Porcellato et al., 2010; Ravesteijn \& Graafland, 2011), as are their loss of skills and obsolescence (European Commission, 2015; Young, 2012).

To a certain extent, unemployment can compensate for the loss of the latent benefits of work through other, non-work activities (Selenko et al., 2011). Having 'purposeful' activities or meaningful patterns of activity was found to reduce the stress associated with unemployment (Ball \& Orford, 2002; Winefield, Tiggeman, \& Winefield, 1992). Waters and Moore (2002) found that both solitary and social leisure activities were just as valued by the unemployed as the employed. Furthermore, both types of activities played a role in reducing latent deprivation and improving psychological health, with social leisure activities contributing more than solitary leisure activities. These findings suggest that doing activities which are valuable to a person will contribute to their well-being. This concurs with the starting point of the capability approach, which was introduced by Amartya Sen $(1980,2005,2009)$. The capability approach offers a framework which focuses on what people value in life. These valued constituents can be expressed by socalled functionings, which represent states and activities that constitute a person's being "various things a person may value doing or being" (Sen, 1999, p. 75), or the very different activities and situations that people consider to be important (Alkire, 2002). Capabilities are the real opportunities, the freedoms people have, to achieve valuable functionings. So, capabilities reflect the freedom of individuals to do what they wish to do, to be who they want to be (Sen, 1999), and to choose any of the alternative combinations of functionings (Sen, 2005). Capabilities represent a person's opportunity and ability to achieve valuable outcomes, taking into account relevant personal characteristics and external factors; in other words, being able and enabled (van der Klink et al., 2016). The capability approach reflects a central theme within the idea of occupational justice; a philosophical perspective on the equitable distribution of societal resources that might contribute to a more just and inclusive society (Hocking, 2017). According to Wilcock and Hocking $(2015$, p. 414), occupational justice refers to equitable or fair opportunities and resources "to do, be, belong and become what people have the potential to be and the absence of avoidable harm." In a paper on so- 
cial exclusion, Sen (2000) discusses social exclusion as capability deprivation. Being excluded from social relations can also lead to other forms of deprivation, thereby further limiting our living opportunities. Social exclusion can, thus, be a part of capability deprivation as well as a cause of a wide range of capability failures. Social exclusion can be regarded as a corrosive disadvantage in terms of Wolff and De-Shalit (2007), where a disadvantage in one domain is likely to spread its effects to other areas. Not achieving a functioning or capability iteratively suppresses the achievement of other functionings.

People can find valued benefits in meaningful jobs rather than bullshit jobs; that's why meaningful jobs are preferred. Seven values that are important to people in their work were identified by interviews among workers in the Netherlands: (1) use of knowledge and skills, (2) development of knowledge and skills, (3) involvement in important decisions, (4) building and maintaining meaningful contacts at work, (5) setting own goals, (6) having a good income, and (7) contributing to something valuable (Abma et al., 2016, p. 38). In this study, we will extend this work by applying the framework of the capability approach to the context of the long-term unemployed. Long-term unemployed are those who have been out of paid employment for at least 12 months but are still available for paid employment (OECD, 2016). We focus on the older long-term unemployed because returning to paid employment is very difficult for them despite the economic growth of recent years. Two research questions were formulated: (1) What are the valuable functionings of older long-term unemployed people? (2) Can older long-term unemployed people achieve the valuable functionings of work in their non-working lives?

\section{Method}

\subsection{Design}

Semi-structured interviews were conducted with longterm unemployed people aged 45 and older. There is no clear definition of what an older unemployed worker is. Some EU studies choose the age of 50 as a starting point, whereas others employ the age of 55 (European Commission, 2016). The age of 45 was taken as a starting point because statistics in the Netherlands have shown that from this point onwards, unemployed workers have greater difficulty regaining paid employment than younger unemployed workers. A qualitative study design was chosen because it elucidates data from the perspectives of the older long-term unemployed themselves. This approach opens the study up to authentic themes, independent from prevailing constructs, instruments, or questionnaires.

\subsection{Sample and Procedure}

Participants were derived from two social service departments in the northern region of the Netherlands, one located in an urban area (200.000 inhabitants) and the other in a more rural area (47.000 inhabitants). Each of the social service departments represented a different labour market region and provided benefits for three municipalities. Their activation programs are bound by national legislation and essentially do not differ much from other programs in the Netherlands. In essence, in the diagnostic phase, the programs make a distinction between the unemployed who need no support, those who are able to find a job with the support of the social services department, and those whose chance of finding a job is negligible.

The social services departments sent a letter to all clients fitting the inclusion criteria: aged 45 or over, applied for benefits in 2009 or 2010 and still received benefits on 1 August 2013. The letter introduced them to the research project and notified them that they might receive a phone call from a researcher to ask whether they wanted to participate and mentioned that participation was voluntary and would not have any consequences for their social benefits. The inclusion of respondents was regulated by a combination of saturation and purposeful sampling: we tried to create proportional variation in location (urban/rural), gender, age group (45-49, 50-54, 55-59, 60-67), and level of education. However, the level of education was often not registered, while the cases that were registered showed that a lower level of education was overrepresented. As a consequence, we decided that we could not use this sampling criterion. First, we divided the research population into rural and urban areas. Second, the possible participants were categorized according to the inclusion criteria of gender and age group. Third, we approached the people in each cell at random by selecting every fifth person in the cell. If a person did not want to participate, we approached the seventh person in the cell. This process was repeated until all characteristics were sufficiently represented.

A total of 202 people met the inclusion criteria, 148 from the urban area and 54 from the rural area. From these 202 people, 93 were approached to participate in the study. From those who were approached, 35 did not want to participate and 38 could not be reached due to outdated phone numbers or a lack of response. A total of 20 respondents were willing to participate in the study. The interviews were conducted in 2013 and 2014.

\subsection{Participant Characteristics}

In Table 1, the characteristics of the participants are listed. The mean age of the 20 participants was 54.5 (SD 5.25; range 46-64). Eleven lived in an urban area and nine in a rural area. Thirteen participants had a lower level of education, five of them had a medium level of education and two participants had a higher level of education. Ten people had been unemployed for five years or less and eight people for considerably longer. Two people were active in paid employment, either doing parttime seasonal work or participating in a program towards self-employment. 
Table 1. Overview of the characteristics of participants in the study.

\begin{tabular}{llllll}
\hline Participants & Gender & Age & Educational level & Duration of unemployment in years & Location \\
\hline 1 & M & 49 & Low & 3 & Urban \\
2 & M & 50 & Low & 5 & Urban \\
3 & M & 48 & Low & 10 & Urban \\
4 & M & 51 & Medium & 10 & Urban \\
5 & M & 64 & Medium & 11 & Urban \\
6 & F & 58 & Low & Never been in paid employment & Urban \\
7 & F & 58 & Low & 7 & Urban \\
8 & F & 57 & Low & 2 & Urban \\
9 & M & 50 & Low & 5 & Urban \\
10 & F & 59 & Medium & 11 & Urban \\
11 & F & 46 & High & $11 ;$ in trajectory towards self-employment & Urban \\
12 & F & 55 & Low & 37 & Rural \\
13 & M & 52 & Medium & 3 & Rural \\
14 & M & 49 & Low & 11 & Rural \\
15 & M & 60 & High & 5 & Rural \\
16 & M & 64 & Medium & 5 & Rural \\
17 & F & 56 & Low & 5 & Rural \\
18 & F & 50 & Low & 20 & Rural \\
19 & M & 53 & Low & 4 & Rural \\
20 & F & 60 & Low & $0 ;$ in part-time seasonal work & Rural \\
\hline
\end{tabular}

\subsection{Interview}

Semi-structured interviews were performed in Dutch with an average length of 1.5 hours. The interviews took place in the participants' own homes, except for two participants, who preferred doing the interview at their local social services department.

First, socio-demographic data were gathered: age, educational background, previous profession, and the length of the period of unemployment. Second, respondents were asked about their valuable functionings. These questions concerned their daily activities, why they performed these activities and how important they rated their activities on a scale of 1 to 10 ( $1=$ not important, $10=$ very important). The respondents were also asked whether certain valued aspects were missing in their lives and whether they thought that they were able to achieve these aspects. In addition, they could indicate how satisfied they were with their lives on a scale of 1 to 10 ( 1 = not satisfied, $10=$ very satisfied $)$.

The interview schedule was tested by the first author through three pilot interviews. These interviews were evaluated by the first author and discussed with the other authors, resulting in some small alterations to the schedule. This improved interview schedule was used in the subsequent interviews.

\subsection{Analysis}

Analyses were conducted using ATLAS.ti 7 software, a qualitative data analysis and research program. The audio of the interviews was recorded, transcribed, and analysed following the phases of inductive thematic analy- sis (Braun \& Clarke, 2006). The interviews were coded independently by authors one and two for all the relevant topics that were discussed. Quotations were considered relevant if they were related to Jahoda's (1981, 1982) concept of latent and manifest benefits, or to the level of achievement of these benefits. After initial coding, demographic information was added for each participant. To develop an interpretive analysis, Jahoda's concept of latent and manifest benefits and Sen's capability approach were used by authors one and five to group the coded topics into potential themes. Codes were merged if they covered the same meaning, while codes were added if required by the data. Subsequently, codes were grouped into sets that shared a broader thematically related foundation, so-called families, while constantly returning to each quote to check its meaning in the context. Based on these families, in-depth descriptions were made of all cases in the study, containing information about work history, activities, benefits, functionings, capability, and well-being. Finally, the cases were analysed for similarities. The analyses were performed in Dutch. Quotations were translated into English by a translation agency.

\section{Results}

\subsection{Valuable Functionings}

The activities and situations that were considered important to the interviewees were social contacts, feeling appreciated, having structure, feeling useful, being active, meaningfulness, autonomy, financial resources, and paid work. 
Social contact was mentioned as a valued functioning, for the contact itself (being around other people) as well as for feeling appreciated:

I used to always be outside, always at work. It's hard for me now, always being inside, staying at home....l sometimes need contact with other people, too. For my language, for a lot of things.....Being around people is important to me. (Participant 1)

I really enjoy being around people. Especially older people.....And when you see how these people think the world of me.... I haven't had that feeling in years, of receiving the occasional compliment. (Participant 12)

Structure was mentioned as another important aspect in people's lives. They felt comfortable with some sort of regularity in their daily lives:

I cycle a lot, I walk a lot. All of that is to maintain that work rhythm and stay reasonably fit. That way, if you do get hired, you won't have to deal with the transition. (Participant 13)

Feeling useful was also found to constitute a valued functioning:

I can at least make myself useful for the $€ 350$ I still get from social services. So I told myself: Yes, I'll help that brother again tomorrow.... might not have a job in society, but I'm making myself useful. (Participant 6)

Meaningfulness was another functioning mentioned across the interviews. It implies being able to do the things that matter to you or that have added value for you personally. For example: "Translating literature. Poems and prose from Romanian to Dutch....It's my life's dream. When I was in secondary school, I dreamed of becoming a literary translator. It's satisfying. Satisfying to me" (Participant 11).

However, finding meaningfulness was found to be a real challenge. As one interviewee stated:

I haven't had that feeling [meaningfulness] for the past three years. So you look for compromises. I have a car that I wash regularly. It's necessary on the one hand, and a way to occupy time on the other. Plus, you're outside. You try to get a sense of satisfaction out of it. But it's not the true sense of satisfaction, like when you're working every day. You try to get something out of it, but it's not really there. (Participant 13)

Autonomy was also mentioned as a highly valued aspect in people's lives. It was said that feeling in control of one's life, being able to make one's own decisions and being independent of institutions was important: "Yes, just to provide for yourself a little, so you're not dependent. That's important to me" (Participant 20).
This functioning was also difficult to achieve. Participants indicated that their autonomy was constrained by the social services:

All the things you have to share. They know everything short of how many hairs you have on your chest and your bum. Hey, you might have to go and sell those for pillow stuffing or something. Aside from that, they want to know everything about you. (Participant 19)

Another valuable functioning that was mentioned was having sufficient financial resources, corresponding with Jahoda's $(1981,1982)$ manifest benefit and Abma et al.'s (2016) functioning income. Being able to afford to do something extra occasionally was something that respondents strongly desired: "What I would really like is to go out for a nice meal once or something like that. Go into the city sometime, doing this and doing that" (Participant 7).

Most participants mentioned that financial resources were hardly sufficient to provide for their livelihood, let alone to spend on treats: "You get knocked back and, hum, you can't keep up the lifestyle you've been accustomed to" (Participant 4). Because the three functionings of meaningfulness, autonomy, and financial resources were hardly accessible to a person on welfare, paid work was often said to be of importance: "Work is important. In plain terms, work makes or breaks it all, really" (Participant 13).

Paid work was therefore also considered to be a valuable functioning according to many participants in the study. Paid work is regarded as valuable not only for the work itself but also because paid work can generate access to other valuable functionings.

Being active, finally, was also considered to be important. Being occupied contributed to one's well-being because the alternative, doing nothing, would make one 'go crazy': "You have to stay busy. If you sit around all day, it's not good for your mental state. So you force yourself to stay busy" (Participant 13).

\subsection{The Ability to Achieve the Functionings}

People's ability to achieve the valuable functionings seemed to depend on an interaction between three characteristics in which participants differed, namely the extent to which their work status changed when they entered the benefit system, the value they attributed to having paid work, and the support they received from the social services. These characteristics are intertwined and will therefore not be discussed separately, but they are combined insofar as their outcomes show overlap.

\subsubsection{Group A: Non-Achievers, Changing Work Status}

A majority of the interviewees (Group A and B; $N=13$, 10 men, 3 women) experienced a change in their work status when they became a benefit recipient. They had been active in paid employment in the past but had 
lost their jobs for various reasons. These people had experienced both the advantages and the disadvantages of paid work but were unsuccessful in finding reemployment and therefore entered the benefit system. For most of them (Group A; $N=9,7$ men, 2 women) it was difficult to adjust to their new, jobless lives:

I've been out of work once in the past, but you can always find another job by applying. I can't search in my field anymore, though. And then suddenly the unemployment office isn't there for you and, yeah, that'll make you sick. (Participant 3 )

These people were still very motivated to work. Men and women did not differ in that respect. Paid work still played a central role in their lives as a valuable functioning, their employment commitment was still high. Because they clearly had a worker identity, it was very frustrating for them to be unemployed and have little or no work perspective. They did not feel supported by their environment, any employers, or the social services. Participants all thought that their age was the main obstacle for employers. They often did not even receive a response to their application letter, which had a negative impact on their situation:

I've done it all. Manufacturing, retail, dental receptionist. I always managed to find work. Up until 45, 46. Then it got really difficult. And then it's just over.....t's depressing when you don't hear anything or when you get a rejection. And then sometimes I just don't apply for a long time. (Participant 17)

The interventions that were offered by the social services to this group, if any, were experienced as obstructive instead of supportive. This was especially the case if people were not allowed to do the things that they wanted (e.g., voluntary work) and/or were obliged to participate in activities that they did not consider useful (e.g., job application training). Hence, for this group unemployment made it difficult to achieve functioning autonomy:

All of the restrictions, the unfairness, the obligation, you know...you have to do something but you're not allowed to do anything...because that's not possible or that's not okay, or there isn't any room. And then I think, hey, I would have gotten off the dole long ago if I'd just been allowed to do my thing. (Participant 16)

I'm not even under obligation to apply for jobs now. So yeah, I, uh, no longer have to apply for jobs. Because they say that they don't know either what kind of work, hum. (Participant 7)

\subsubsection{Group B: Achievers, Changing Work Status}

Within the group of participants whose work status changed upon receiving benefits, there were also peo- ple (Group B; N = 4, 3 men, 1 woman) who could accept their new jobless lives and who attributed less value to paid work:

I don't want to stress out about this, either. About the job that's never going to happen again anyway. I did at first, though. Wrote stacks of applications and the like. Then you just know, the odds are getting worse. That's when I think, okay you can put a huge amount of energy into it, but it's not going to lead to anything. (Participant 10)

Instead, they adapted to their new situation by starting to attribute more value to other functionings, such as social contact, feeling appreciated, having structure, feeling useful, being active, meaningfulness.

\subsubsection{Group C: Achievers, No Change in Work Status}

There was also a group of interviewees whose work status did not change when they entered the benefit system (Group C; $N=7,1$ man, 6 women). A few of them $(n=4)$ applied for benefits due to the termination of their relationship (e.g., through divorce) after always having taken care of the children and the household. These people had never been active in a paid job (or had been only a very long time ago); their spouses provided for them financially. Now that they had become single, they were still performing the same activities as they had before; only now, they were financially depended on the benefits they received. They did not have a worker identity and did not really miss paid employment for its latent benefits, because they had little or no experience with it: "My last job was in a nursing home in Groningen. I got married in 1976, which is when I quit" (Participant 12).

Other interviewees within this group $(n=3)$ had always had paid work and continued their activities in the economic domain; as a result, their work identity did not change either. Some of them did seasonal or part-time work while others worked off the payroll. Nevertheless, as their income was beneath the standard, they still qualified for the benefits. The interviewees whose work status remained unchanged, mostly women, were quite satisfied with their lives. This group didn't experience a loss of functionings due to unemployment and did not strive to achieve other functionings such as income.

The interventions applied by the social services differed between individuals. Some of them were basically neglected, while others were in a reintegration program. Despite the different interventions, participants felt supported in their choices. Most of the neglected people had the personal capacities to achieve their functionings and needed little support from the social services. The participants that were in a reintegration program evaluated this intervention positively. In conclusion, it seems that all of these people were enabled to achieve valued outcomes which contributed to their well-being: 
I'm very satisfied. Listen, I could get to the point where I sit down and be like: Oh, I've got it so rough, and, uh.... Other people say that; they go: Oh, you've got it so rough. I don't think so. That's not how I am. (Participant 18)

It's self-respect, is what it is. Ultimately, you managed to find paying work, contact with people who share the same interests. More positivity. Better presence. That's also good for the social contacts, good for the social life. (Participant 11)

\section{Discussion and Conclusion}

In this article, we used the frameworks of Jahoda's latent deprivation theory and Sen's capability approach to explore the valuable functionings of older long-term unemployed people and their ability to achieve valued outcomes.

We identified nine functionings which were noted as important across the interviews: social contact, feeling appreciated, structure, feeling useful, meaningfulness, autonomy, financial resources, paid work, and being active. These valuable functionings partly overlap with the valuable functionings that were found in a qualitative study among older people aged 63 to 93 years (Stephens, Breheny, \& Mansvelt, 2015). Although most of them had reached retirement age, their functionings corresponded to a large extent to the benefits of employment that Jahoda (1981) described. This finding is also in line with a study by Paul, Vastamäki, and Moser (2016), which found no differences in the importance of life goals between employed and unemployed individuals.

The valuable functionings described above were at least to some extent accessible to people through the activities they were doing. As mentioned before, previous studies confirm the opportunities of unemployed people to access latent benefits (Selenko et al., 2011; Waters \& Moore, 2002). However, we found that participants in our study differed from each other in achieving the outcomes that they valued most. People who had the ability to achieve valued outcomes were active in the same domains as people who did not have the ability to achieve these outcomes. However, the change in work status, the value attributed to paid employment and the support received from the social services influenced their ability to experience activities as a free choice and hence as a valuable outcome.

Most participants still had a worker identity and attributed great value to paid work, having a high level of employment commitment. This finding is partly in line with results from a meta-analysis by Paul and Moser (2006), which showed almost equal levels of employment commitment for both employed and unemployed people. It also corresponds with studies by Varekamp, Knijn, Bos, and van Wel (2014) and Shildrick, MacDonald, Webster, and Garthwaite (2012), which reported that a majority of the long-term unemployed would prefer a job over welfare benefits. Other participants acquiesced in their jobless lives in which paid work was not a valuable functioning. Either type of participant was active in a mix of activities, varying from physically active and physically passive activities to informal work. These activities were sufficient for achieving valued outcomes and wellbeing in participants who had no worker identity and did not aspire to paid work. This was not the case among participants who still highly valued paid work and who did not feel supported by employers or the social services. Not having the ability to be active in valued activities was experienced as frustrating. In sum, long-term unemployed people differ in the outcomes that they value and in the ability to achieve their valued outcomes, the value attributed to paid employment being crucial in experiencing these valued outcomes. This finding is congruent with studies by Creed, Lehmann, and Hood (2009), Hollederer (2015) and Paul and Moser (2006), who all found that high levels of employment commitment lead to lower levels of well-being in unemployed people. As a consequence, people who are willing to work but are expected to have low chances of re-employment seem to be especially at risk of health deprivation. They lack the necessary commodities to achieve their valued outcomes. Moreover, this group is being neglected according to the capability approach, because they are unable to find re-employment themselves and are not supported into work by employers or the social services. This can be seen as a form of occupational injustice because the environment "in which all people's opportunities to engage in occupation are just, health-promoting and meaningful" (Hocking, 2017, p. 33) is lacking.

Four of the valuable functionings-meaningfulness, autonomy, financial resources, and paid work-were reported as hardly achievable. An explanation for this finding could be that, at the time when the interviews took place, Dutch social security law conflicted with the capability approach's process and opportunity aspects of freedom. The process aspect refers to "having the levers of control in one's own hand" (Sen, 1993). The opportunity aspect of freedom is concerned with our actual capability to achieve. It relates to the real opportunities we have of distinguishing things that we can and do value, no matter what the process is through which that achievement comes about (Sen, 1993). The unemployed were either obliged to participate in programs that did not necessarily add value for them, or they were denied access to activities in which they did wish to participate, for example, voluntary work. In general, those with better chances of re-employment were supported more in their job-finding process than those with fewer chances in the labour market (Varekamp et al., 2014). Interventions designed for most people may be counterproductive for social or occupational justice because the values and desires of some groups are neglected (Bailliard, 2016). This finding illustrates that the valuable functionings of the welfare recipients were not always acknowledged or acted upon by the social services. 
We have used the capability model as one of the frameworks to investigate our results. One of the aspects that distinguishes the capability model from many other models is that it is explicitly normative. It gives people the entitlement to be able and enabled to live a valuable and flourishing life, "beings and doings people have reason to value" (Sen, 1999). As such, the capability model is not only meant to explain, but also to act as an agent of change. Our study showed that the then prevalent social system led to social exclusion, experienced by at least the group that still had a worker identity. They felt socially excluded and had severe deprivations of important (latent) benefits and capabilities. They could not achieve these benefits in their unemployed state. This is partly due to how macroeconomic policies to reduce government budget deficits lead to a social policy based on the neo-liberal market-oriented welfare paradigm, with a strong emphasis on monitoring and strict law enforcement, and the tightening up the conditions for access to benefits, as well as a reduction in the levels of, and durations of, unemployment and disability benefits.

Several developments have led to a call for action and a paradigm shift. Firstly, policymakers have begun to realise that monitoring and sanctions, which are considered as traditional instruments within this approach, are costly to implement and often ineffective. Secondly, these doubts about the effectiveness of traditional instruments have been fuelled by new behavioural insights, such as positive health, positive psychology, and the capability approach which emphasize people's selfmanagement, needs, and value assessments aimed at enabling them to live a good life. Thirdly, studies such as this reveal the de-humanising aspects of this policy to politicians and policymakers.

So, we see a paradigm shift in social policy in the Netherlands from workfare and activation to a social investment and capacitating approach. This paradigm shift has not yet been implemented in actual policy practices (Hemerijck, 2013, 2017) but has led to a sense of urgency especially at the level of municipalities culminating in the launch of local experiments which have similarities with basic income approaches to social policy (Groot, Muffels, \& Verlaat, 2019).

A strength of this study was the use of in-depth personal interviews, which took place in the participants' own homes with the assurance of confidentiality. This informal setting enabled participants to talk at length and in-depth about their experiences of being unemployed. Another strength was that saturation was reached during the interviews. For this reason, we are quite confident that the findings are valid for other long-term unemployed people as well. Finally, we used two theoretical frameworks to develop an interpretive analysis.

A limitation was that we did not build in a feedback loop, a so-called member check, in which we would have checked our interpretation of the data with the participants (Doyle, 2007). In addition, we were not able to select participants fully in accordance with the purposeful sampling method, due to lacunas in the municipalities' registration system. The educational level of the unemployed was often not registered and their contact information was not always up to date. Therefore, it was quite difficult to approach potential participants.

This study resulted in some interesting findings regarding the values of the long-term unemployed and the accessibility of these values from a capability approach perspective, which can be helpful for professionals working with this target group. The findings illustrate the need for tailor-made support of unemployed people. A personalized approach through enhanced choice is viewed as a key mechanism for developing empowerment and independence in clients (Leadbeater, 2004). The capability approach offers an approach centred on the individual in his or her own context, with the emphasis on each individual's valued outcomes. A survey among a large representative group of long-term unemployed people could be useful to identify the number of unemployed people who might need this personalized approach.

\section{Acknowledgments}

The authors are grateful to the long-term unemployed people who participated in this research and to the staff of social services who assisted in recruiting participants.

\section{Conflict of Interests}

The authors declare no conflict of interests.

\section{References}

Abma, F. I., Brouwer, S., de Vries, H. J., Arends, I., Robroek, S. J. W., Cuijpers, M. P. J., . . . van der Klink, J. J. L. (2016). The capability set for work: Development and validation of a new questionnaire. Scandinavian Journal of Work Environment and Health, 42(1), 34-42.

Alkire, S. (2002). Valuing freedoms: Sen's capability approach and poverty reduction. Oxford: Oxford University Press.

Bailliard, A. (2016). Justice, difference, and the capability to function. Journal of Occupational Science, 23(1), 3-16.

Ball, M., \& Orford, J. (2002). Meaningful patterns of activity amongst the long-term inner city unemployed: A qualitative study. Journal of Community \& Applied Social Psychology, 12(6), 377-396.

Braun, V., \& Clarke, V. (2006). Using thematic analyses in psychology. Qualitative Research in Psychology, 3(2), 77-101.

Creed, P. A., Lehmann, K., \& Hood, M. (2009). The relationship between core self-evaluations, employment commitment and well-being in the unemployed. Personality and Individual Differences, 47(4), 310-315.

de Graaf-Zijl, M., van der Horst, A., van Vuuren, D., Erken, H., \& Luginbuhl, R. (2015). Long-term unem- 
ployment and the Great Recession in the Netherlands: Economic mechanisms and policy implications. De Economist, 163(4), 415-434.

Doyle, S. (2007). Member checking with older women: A framework for negotiating meaning. Health Care for Women International, 8, 888-908.

Duell, N., Thurau, L., \& Vetter, T. (2016). Long-term unemployment in the EU: Trends and policies. Munich: Economix Research \& Consulting. Retrieved from https://www.bertelsmann-stiftung.de/fileadmin/ files/user_upload/Studie_NW_Long-term_ unemployment.pdf

Dur, R., \& Lent, M. (2019). Socially useless jobs. Industrial Relations: A Journal of Economy and Society, 58(1), 3-16.

Equinet. (2012). Tackling ageism and discrimination. An Equinet perspective in the context of the European year for active ageing and solidarity between generations. Equinet Europe. Retrieved from http://www. healthyageing.eu/sites/www.healthyageing.eu/files/ resources/age_perspective__merged___equinet_ en.pdf

European Commission. (2015). Employment and social developments in Europe 2015. European Commission. Retrieved from http://ec.europa.eu/social/ BlobServlet?docld=14951\&langld=en

European Commission. (2016). Employment, social affairs \& inclusion: EU employment and social situation (Quarterly Review). Luxembourg: Publications Office of the European Union. Retrieved from http://ec.europa.eu/social/BlobServlet?docld= 15397\&langld=en

Feather, N. T., \& Bond, M. J. (1983). Time structure and purposeful activity among employed and unemployed university graduates. Journal of Occupational Psychology, 56(3), 241-254.

Fryer, D. (1998). The simultaneity of the unsimultaneous: A conversation between Marie Jahoda and David Fryer. Journal of Community \& Applied Social Psychology, 8, 89-100.

Fryer, D., \& Fagan, R. (1993). Coping with unemployment. International Journal of Political Economy, 23(3), 95-120.

Fryer, D., \& Fagan, R. (2003). Toward a critical community psychological perspective on unemployment and mental health research. American Journal of Community Psychology, 32(1/2), 89-96.

Graeber, D. (2018). Bullshit jobs: The rise of pointless work, and what we can do about it. London: Penguin Books.

Groot, L., Muffels, R., \& Verlaat, T. (2019). Welfare states' social investment strategies and the emergence of Dutch experiments on a minimum income guarantee. Social Policy \& Society, 18(2), 277-287.

Hemerijck, A. (2013). Changing welfare states. Oxford: Oxford University Press.

Hemerijck, A. (Ed.). (2017). The uses of social investment. Oxford: Oxford University Press.
Hocking, C. (2017). Occupational justice as social justice: The moral claim for inclusion. Journal of Occupational Science, 24(1), 29-42.

Hollederer, A. (2015). Unemployment, health and moderating factors: The need for targeted health promotion. Journal of Public Health, 23(6), 319-325.

Jahoda, M. (1981). Work, employment, and unemployment. Values, theories, and approaches in social research. American Psychologist, 36(2), 184-191.

Jahoda, M. (1982). Employment and unemployment: $A$ social-psychological analysis. Cambridge: Cambridge University Press.

Leadbeater, C. (2004). Personalisation through participation: A new script for public services. London: Demos.

Muller, J. \& Waters, L. (2012). A review of the Latent and Manifest Benefits (LAMB) scale. Australian Journal of Career Development, 21(1), 31-37.

Nybom, J. (2013). Activation and 'coercion' among Swedish social assistance claimants with different work barriers and socio-demographic characteristics: What is the logic? International Journal of Social Welfare, 22(1), 45-57.

OECD. (2016). Long-term unemployment. In OECD factbook 2015-2016: Economic, environmental and social statistics (pp. 134-136). Paris: OECD Publishing.

Paul, K. I., \& Batinic, B. (2010). The need for work: Jahoda's latent functions of employment in a representative sample of the German population. Journal of Organizational Behavior, 31(1), 45-64.

Paul, K. I., \& Moser, K. (2006). Incongruence as an explanation for the negative mental health effects of unemployment: Meta-analytic evidence. Journal of Occupational and Organizational Psychology, 79(4), 595-621.

Paul, K. I., Vastamäki, J., \& Moser, K. (2016). Frustration of life goals mediates the negative effect of unemployment on subjective well-being. Journal of Happiness Studies, 17(2), 447-462.

Paulsen, R. (2014). Empty labor: Idleness and workplace resistance. Cambridge: Cambridge University Press.

Porcellato, L., Carmichael, F., Hulme, C., Ingham, B., \& Prashar, A. (2010). Giving older workers a voice: Constraints on the employment of older people in the north west of England. Work, Employment and Society, 24(1), 85-103.

Ranzijn, R. (2004). Role ambiguity: Older workers in the demographic transition. Ageing International, 29(3), 281-308.

Ravesteijn, J., \& Graafland, H. (2011). 45-plussers op de arbeidsmarkt. Meer uitstroom van $45+$ uit de WWB. Kennisproduct Gildeproject re-integratie [45+ on the labour market, more $45+$ stream out of social benefits Knowledgeproduct Gildeproject reintegration]. Amsterdam: Gildenetwerk.

Selenko, E., Batinic, B., \& Paul, K. I. (2011). Does latent deprivation lead to psychological distress? Investigating Jahoda's model in a four-wave study. Journal of Occupational and Organizational Psychology, 84(4), 723-740. 
Sen, A. K. (1980). Equality of what? In S. M. McMurrin (Ed.), The Tanner lectures on human values (pp. 197-220). Salt Lake City, UT: University of Utah Press.

Sen, A. K. (1993). Markets and freedoms: Achievements and limitations of the market mechanism in promoting individual freedoms. Oxford Economic Papers, 45(4), 519-541.

Sen, A. K. (1999). Development as freedom. New York, NY: Knopf.

Sen, A. K. (2000). Social exclusion: Concept, application and scrutiny (Social Development Papers No. 1). Mandaluyong: Office of Environment and Social Development, Asian Development Bank.

Sen, A. K. (2005). Human rights and capabilities. Journal of Human Development, 6(2), 151-166.

Sen, A. K. (2009). The idea of justice. London: Allen Lane. Shildrick, T., MacDonald, R., Webster, C., \& Garthwaite, K. (2012). Poverty and insecurity. Bristol: Policy Press.

Social Security Administration. (2014). Security programs throughout the world: Europe, 2014. Washington, DC: Social Security Administration. Retrieved from https://www.ssa.gov/policy/docs/progdesc/ssptw/ 2014-2015/europe/ssptw14europe.pdf

Stephens, C., Breheny, M., \& Mansvelt, J. (2015). Healthy ageing from the perspective of older people: A capability approach to resilience. Psychology \& Health, 30(6), 715-731.

Stiglbauer, B., \& Batinic, B. (2012). The role of Jahoda's latent and financial benefits for work involvement: A longitudinal study. Journal of Vocational Behavior, 81(2), 259-286.

Thomson, P. (2019). The Taylor Review: A platform for progress? Good work: The Taylor Review of modern working practices. New Technology, Work and Employment, 34(2), 106-110.

Timmermann, C. (2018). Contributive justice: An exploration of a wider provision of meaningful work. Social Justice Research, 31(1), 85-111. van Berkel, R., de Graaf, W., \& Sirovatka, T. (2012). Introduction. International Journal of Sociology and Social Policy, 32(5), 1.

van Dalen, H. P., Henkens, K., \& Schippers, J. (2009). Dealing with older workers in Europe: A comparative survey of employers, attitudes and actions. Journal of European Social Policy, 19(1), 47-60.

van Dalen, H. P., Henkens, K., \& Schippers, J. (2010). Productivity of older workers: Perceptions of employers and employees. Population and Development Review, 36(2), 309-330.

van der Klink, J. J. L., Bültmann, U., Burdorf, A., Schaufeli, W. B., Zijlstra, F. R. H., Abma, F. I., . . van der Wilt, G. J. (2016). Sustainable employability: Definition, conceptualization, and implications. A perspective based on the capability approach. Scandinavian Journal of Work Environment and Health, 42(1), 71-79.

Varekamp, I., Knijn, T., Bos, P., \& van Wel, F. (2014). Psychosocial factors predicting job search behaviour of long-term welfare recipients in the Netherlands. European Journal of Social Security, 16(4), 347-370.

Waters, L. E., \& Moore, K. A. (2002). Reducing latent deprivation during unemployment: The role of meaningful leisure activity. Journal of Occupational and Organizational Psychology, 75(1), 15-32.

Wilcock, A. A., \& Hocking, C. (2015). An occupational perspective of health (3rd ed.). Thorofare, NJ: Slack.

Winefield, A. H., Tiggeman, M., \& Winefield, H. R. (1992). Spare time use and psychological well-being in employed and unemployed young people. Journal of Occupational and Organizational Psychology, 65(4), 307-313.

Wolff, J., \& De-Shalit, A. (2007). Disadvantage. Oxford: University Press.

Young, C. (2012). Losing a job: The nonpecuniary cost of unemployment in the United States. Social Forces, 91(2), 609-633.

\section{About the Authors}

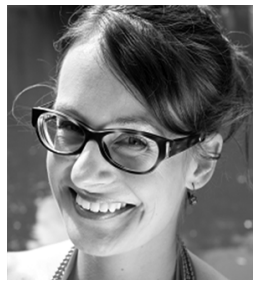

Nienke Velterop holds a masters' degree in Psychology. She currently works as a Psychologist in mental health care. Previously, she worked as a lecturer in Applied Psychology at the Hanze University of Applied Sciences Groningen while working on her PhD project. Her research focuses on (long-term) unemployed people and their access to work-related benefits and well-being using the latent deprivation theory and capability approach. Her research aims to identify factors that contribute to these benefits which can improve well-being.

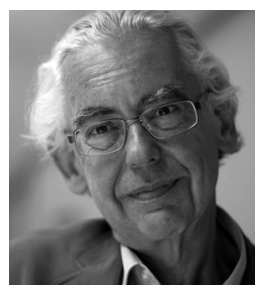

Jac van der Klink is Emeritus Professor of Sustainable Employability and Mental Health at Work at Tilburg University and Extraordinary Professor at Optentia, North-West University of South Africa. With a consortium, he developed a model and a questionnaire on sustainable employability based on the capability approach. His present research focuses on developing additional (implementation) tools on this subject. He is also involved with the professionalisation (among others, guideline development and implementation) of professionals in the field of mental health and work. 


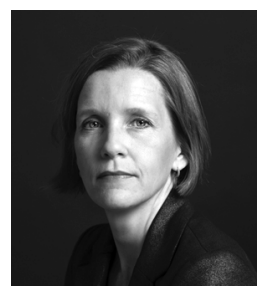

Sandra Brouwer (PhD) is Professor of Occupational Medicine at the Department of Health Sciences at the University Medical Centre Groningen. Her research focuses on labour market participation of people with disabilities. With her research, she aims to prevent employees with chronic disease from moving into long-term disability or early retirement. She works in close collaboration with professionals and stakeholders in the areas of occupational and insurance medicine and rehabilitation medicine.

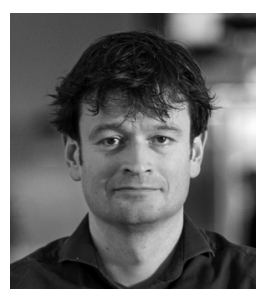

Hilbrand Oldenhuis is Professor at the School of Communication, Media \& IT, Hanze University of Applied Sciences, Groningen, in the Netherlands. His research aims to combine psychology and data science and focuses on the supporting role that personalised technology can play in improving sustainable employability and work-related health outcomes.

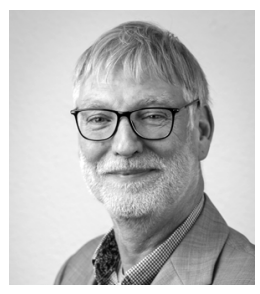

Louis Polstra is a Labour Participation Professor at Hanze University of Applied Sciences, Groningen. His research focuses on the professionalization of frontline workers, employed at Dutch local welfare agencies. He developed the professional standard and the profile of these frontline workers. In addition, he is involved in several studies on the labour integration of refugees and social activation programs for long term (young) unemployed. 